\title{
Nanoscale
}

Check for updates

Cite this: Nanoscale, 2021, 13, 3285

\section{Selective deposition of metal oxide nanoflakes on graphene electrodes to obtain high-performance asymmetric micro-supercapacitors $\uparrow$}

\author{
Zhenyuan Xia, (D) *a,b Viktoriia Mishukova, ${ }^{c}$ Szymon Sollami Delekta, (D) ${ }^{\mathrm{c}}$ Jinhua Sun, ${ }^{\mathrm{a}}$ \\ Jaime S. Sanchez, ${ }^{a}$ Jiantong Li (D) *c and Vincenzo Palermo (D) ${ }^{a, b}$
}

\begin{abstract}
To meet the charging market demands of portable microelectronics, there has been a growing interest in high performance and low-cost microscale energy storage devices with excellent flexibility and cycling durability. Herein, interdigitated all-solid-state flexible asymmetric micro-supercapacitors (A-MSCs) were fabricated by a facile pulse current deposition (PCD) approach. Mesoporous $\mathrm{Fe}_{2} \mathrm{O}_{3}$ and $\mathrm{MnO}_{2}$ nanoflakes were functionally coated by electrodeposition on inkjet-printed graphene patterns as negative and positive electrodes, respectively. Our PCD approach shows significantly improved adhesion of nanostructured metal oxide with crack-free and homogeneous features, as compared with other reported electrodeposition approaches. The as-fabricated $\mathrm{Fe}_{2} \mathrm{O}_{3} / \mathrm{MnO}_{2} \mathrm{~A}-\mathrm{MSCs}$ deliver a high volumetric capacitance of $110.6 \mathrm{~F}$ $\mathrm{cm}^{-3}$ at $5 \mu \mathrm{A} \mathrm{cm}{ }^{-2}$ with a broad operation potential range of $1.6 \mathrm{~V}$ in neutral LiCl/PVA solid electrolyte. Furthermore, our A-MSC devices show a long cycle life with a high capacitance retention of $95.7 \%$ after 10000 cycles at $100 \mu \mathrm{A} \mathrm{cm}{ }^{-2}$. Considering its low cost and potential scalability to industrial levels, our PCD technique could be an efficient approach for the fabrication of high-performance MSC devices in the future.
\end{abstract}

Received 2nd October 2020 Accepted 8th January 2021 DOI: 10.1039/dOnr07076a rsc.li/nanoscale

\section{Introduction}

Nowadays, electrical energy storage technology has revolutionized the whole world and changed our daily life with numerous portable electronic devices such as smartphones, digital watches, wireless earbuds and other wearable devices. ${ }^{1,2}$ Due to the importance of energy storage devices, the 2019 Nobel Prize in Chemistry was awarded for the pioneering work on the rechargeable Li-ion battery. Meanwhile, supercapacitors, as another leading electrochemical energy storage technology, have also attracted intensive interest in both academia and industry in the last decade. ${ }^{3}$ In particular, planar micro-supercapacitors (MSCs) possessing a thin-layer structure, high power density, rapid charging/discharging capabilities and long cycle life are considered to be promising microscale power sources for on-chip electronic systems. ${ }^{4-6}$ Carbon-based

\footnotetext{
${ }^{a}$ Department of Industrial and Materials Science, Chalmers University of Technology, Hörsalsvägen 7B, 41258 Göteborg, Sweden. E-mail: zhenyuan@chalmers.se ${ }^{b}$ Istituto per la Sintesi Organica e la Fotoreattività, CNR, via Gobetti 101, 40129 Bologna, Italy

${ }^{c}$ School of Electrical Engineering and Computer Science, KTH Royal Institute of Technology, Electrum 229, 16440 Kista, Sweden.E-mail: jiantong@kth.se $\dagger$ Electronic supplementary information (ESI) available. See DOI: 10.1039/ d0nr07076a
}

MSCs are excellent candidates for microscale power sources compared with conventional stacked-geometry supercapacitors, as they possess integrated thin-film electrodes with short ionic diffusion distances and separator-free structures. Besides this, the fabrication of MSCs with a wide working voltage window is a promising approach for achieving both high energy density and power density. ${ }^{7}$

Asymmetric supercapacitors (ASCs), consisting of two different electroactive materials as positive and negative electrodes, could make full use of two different potential windows in the same cell and significantly increase the overall energy density of devices. To date, transition metal oxides have been intensively studied in ASCs since they could offer high specific capacitance by taking advantage of ultrafast surface redox reactions of transition metal cations. ${ }^{7,8}$ According to the working potential windows of various transition metal oxides in aqueous electrolytes, most of the oxides are used as positive electrode materials with a stable potential range of around $0-1$ $\mathrm{V}$ (vs. SCE), such as pseudocapacitive oxides $\mathrm{MnO}_{2}, \mathrm{ZnO}$ and battery-type oxides $\mathrm{Co}_{3} \mathrm{O}_{4}, \mathrm{~V}_{2} \mathrm{O}_{5}, \mathrm{SnO}_{2}$, NiO, etc. ${ }^{9-15}$ On the other hand, there are few studies reporting negative electrode materials with a working potential range below $0 \mathrm{~V}(v s$. SCE), which includes $\mathrm{Fe}_{2} \mathrm{O}_{3}, \mathrm{MoO}_{3}$, and metal nitrides (VN), etc. ${ }^{16-19}$ Among these oxides, $\mathrm{MnO}_{2}$ and $\mathrm{Fe}_{2} \mathrm{O}_{3}$ as positive and negative electrode materials, respectively, are the most promising candi- 
dates for ASC devices because of their high theoretical capacitance, low cost, abundance and environmental friendliness. Moreover, the well-separated potential windows of $\mathrm{MnO}_{2}(-0.1$ to $0.8 \mathrm{~V} v s$. SCE) and $\mathrm{Fe}_{2} \mathrm{O}_{3}(-0.9$ to $0 \mathrm{~V}$ vs. SCE) could significantly increase the operating voltage of ASCs in aqueous electrolytes.

In order to assemble planar ASCs for on-chip integration, various fabrication strategies, such as photolithography, laser scribing, screen/inkjet printing, and electrodeposition have been developed to pattern carbon and other electro-active materials into interdigital electrodes to form asymmetric microsupercapacitors (A-MSCs). ${ }^{20-27}$ Among these approaches, printing is a cost-effective, cheap, fast and scalable approach for facile fabrication of micropattern electrodes. Conductive materials (e.g., active carbon, carbon nanotubes, nanofibers, and graphene) can also be printed to give interdigitated eletrodes. ${ }^{23}$ In comparison with screen printing, inkjet printing is a flexible and non-contact method that allows precise control of high-resolution patterning without the need for prepatterned masks. However, direct inkjet printing has some limitations: unlike screen printing, which could easily pattern carbon materials and pseudo-capacitive metal oxide mixtures with sufficient thickness, inkjet printing is not suitable for thick patterns. More importantly, micro-printing asymmetric electrodes composed of two different materials would require two printing nozzles and a precise alignment of the two printing patterns, to avoid shortcuts or defects. ${ }^{28,29}$

Unlike the inkjet printing technique, electrodeposition has its unique advantages in thin film fabrication of transition metal oxide materials. Electrodeposition is a mature and scalable technique for nanocrystalline metal plating or metal oxide functional coating in industry. It allows electrosynthesis of metal oxides from solution of metal salts and the subsequent deposition onto any complex-shape substrates through a one-step process..$^{21,30-32}$ In addition, by tuning the electrochemical conditions (e.g. pulse or direct current output, deposition time, electrolytes), we can spatially control the loading amount and surface morphology of metal oxide on selected electrodes. ${ }^{33-40}$ Although electrodeposition has been intensively employed in the fabrication of nanostructured metal oxide films for bulk supercapacitors, ${ }^{41,42}$ there are still some challenges in this thin film formation process. For example, conventional anodic or cathodic direct current deposition of metal oxides will result in internal stresses on the substrates with the formation of delamination layers after coating, which is unfavorable for stable MSC electrodes. Besides, metal oxide materials usually suffer from poor electronic and ionic conductivity, affecting the rate capability and cycling stability of the ASC devices.

These challenges can be overcome by the introduction of new electrochemical deposition techniques and the combination of advanced current collectors with metal oxides. Herein, we used pulse current deposition (PCD) as an alternative cost-effective and simple technique ${ }^{43,44}$ for the fabrication of A-MSCs based on pseudo-active metal oxide $\left(\mathrm{MO}_{x}\right)$ nanomaterials and graphene-based current collectors. Generally, electrochemically exfoliated graphene (EG) was inkjet printed on a Kapton film ${ }^{23}$ to form interdigitated patterns, which served as reliable conductive deposition substrates, thanks to the high electrical conductivity, excellent electrochemical stability, large specific surface area and low cost of graphene. In our exfoliation process, the total cost including those of starting material graphite foil ( $c a .0 .5 €$ per g), electrolyte $0.1 \mathrm{M}$ $\left(\mathrm{NH}_{4}\right)_{2} \mathrm{SO}_{4}$ (ca. $1 €$ per $100 \mathrm{~mL}$ ), and power consumption (ca. 1 $€$ per $\mathrm{kW} \mathrm{h}$ ) is less than $5 €$ per $\mathrm{g}$ on the lab scale. Then, $\mathrm{MnO}_{2}$ and $\mathrm{Fe}_{2} \mathrm{O}_{3}$ were selected as positive and negative electrode materials, respectively, with well-separated potential windows and matchable capacitances. Crack-free and mesoporous $\mathrm{MnO}_{2}$ and $\mathrm{Fe}_{2} \mathrm{O}_{3}$ thin films were fabricated by selective PCD coating on the EG layer and subsequent annealing treatment. To the best of our knowledge, there is no previous research using pulse electrodeposition in micro-scale supercapacitor applications. Our results indicated that the PCD method could significantly improve the coating uniformity, boosting the cycling stability of our prepared A-MSC devices, as compared with the conventional direct current deposition approach. The current technique described here is promising for the rapid fabrication of high-performance A-MSCs with high versatility of pseudo-capacitive metal oxide materials.

\section{Results and discussion}

Fig. 1 shows the fabrication process of $\mathrm{Fe}_{2} \mathrm{O}_{3} / \mathrm{MnO}_{2}$-based A-MSCs. Generally, it was divided into the following steps. First, conductive EG inks were printed on a Kapton substrate to obtain planar interdigitated micropatterns. After annealing treatment of the EG layer, either $\mathrm{MnO}_{x}$ or $\mathrm{FeOOH}$ nanoflakes were electrodeposited on the EG pattern with a two-electrode configuration (EG as the working electrode and a Pt wire as the counter electrode). Then, the obtained samples were annealed at $300{ }^{\circ} \mathrm{C}$ to convert the deposited precursors into either $\mathrm{Fe}_{2} \mathrm{O}_{3}$ or $\mathrm{MnO}_{2}$. For the single metal oxide based MSCs, $1 \mathrm{M} \mathrm{LiCl}$ was used as the aqueous electrolyte for either $\mathrm{Fe}_{2} \mathrm{O}_{3}$ or $\mathrm{MnO}_{2}$ based electrodes. For A-MSCs, solid electrolyte of $\mathrm{LiCl} / \mathrm{PVA}$ gels was used to fabricate the all-solid-state $\mathrm{Fe}_{2} \mathrm{O}_{3} / \mathrm{MnO}_{2} \mathrm{~A}-\mathrm{MSCs}$ (named $\mathrm{Fe}-\mathrm{Mn}$ ).

The electrosynthesis and deposition process of $\mathrm{MO}_{x}$ by the anodic approach can be described by the following equations: ${ }^{45}$

Step 1:

$$
\mathrm{M}_{(\mathrm{aq})}^{2+} \rightarrow \mathrm{M}^{3+}{ }_{(\mathrm{ads})}+\mathrm{e}^{-}
$$

Step 2:

$$
\mathrm{M}^{3+}{ }_{(\mathrm{ads})}+2 \mathrm{H}_{2} \mathrm{O} \rightarrow \mathrm{MO}(\mathrm{OH})_{(\mathrm{ads})}+3 \mathrm{H}^{+}
$$

Step 3:

$$
\mathrm{MO}(\mathrm{OH})_{(\mathrm{ads})} \rightarrow \mathrm{MO}_{x}+\mathrm{H}^{+}+\mathrm{e}^{-}
$$

The proposed mechanism for anodic deposition of manganese oxide involves three steps: (1) oxidation of cationic $\mathrm{Mn}^{2+}$ precursors in the solution near the anode electrodes; (2) and the subsequent hydrolysis of $\mathrm{Mn}^{3+}$ to form the $\mathrm{MnO}(\mathrm{OH})$ inter- 


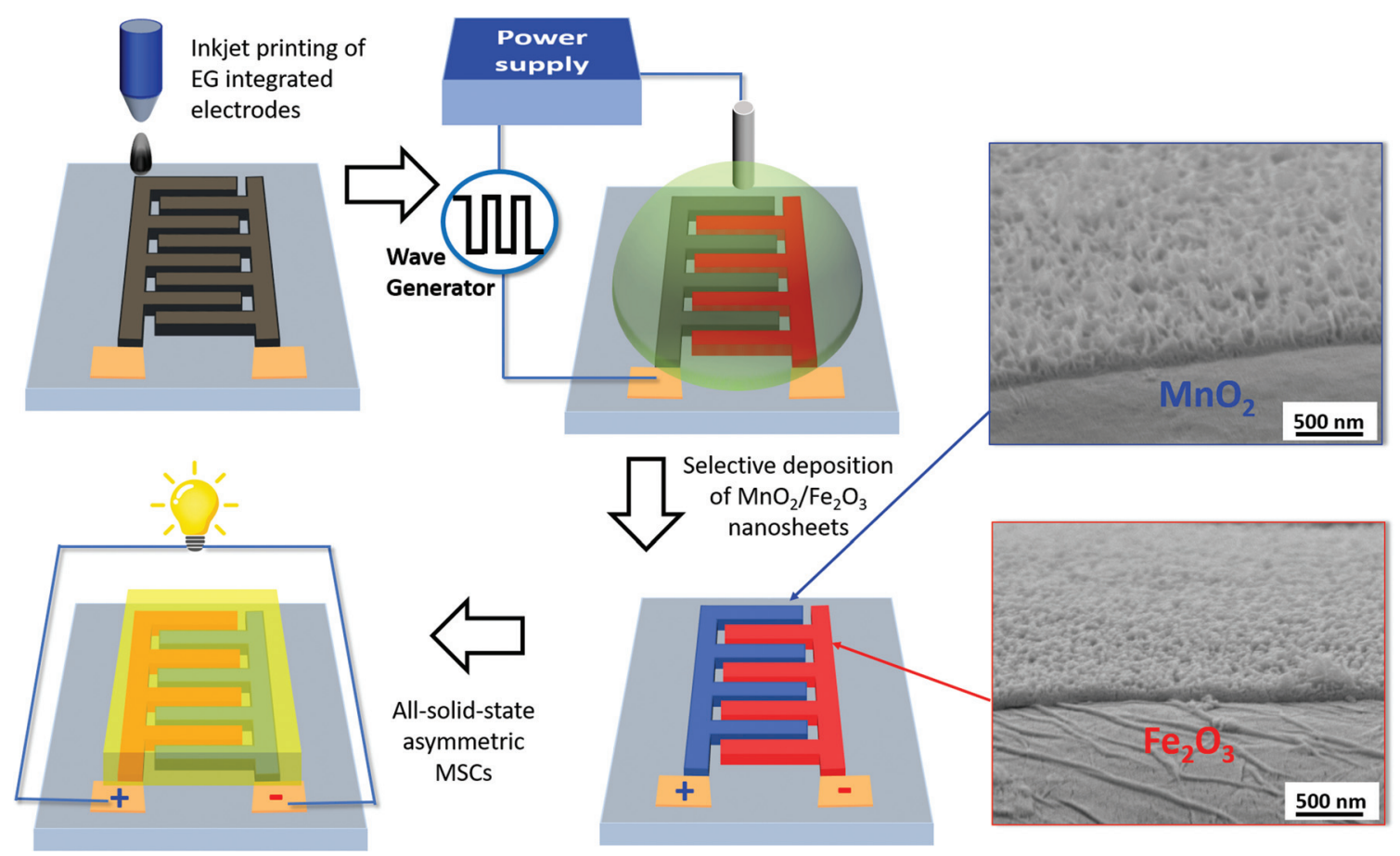

Fig. 1 Schematic illustration of the electrochemical deposition process for $\mathrm{Fe}_{2} \mathrm{O}_{3}$ and $\mathrm{MnO}_{2}$ based inkjet-printed graphene A-MSCs (inset, crosssection SEM images of $\mathrm{Fe}_{2} \mathrm{O}_{3}$ and $\mathrm{MnO}_{2}$ nanoflakes).

mediate which precipitates on the anode electrode; (3) in the last step, the adsorbed manganese hydroxide is further oxidized to $\mathrm{MnO}_{2}$ with the release of a proton. Manganese acetate (MnAc) was selected as the precursor material for electrodeposition of $\mathrm{MnO}_{2}$, because acetate counterions could reduce the potential at which film deposition occurs and results in a high deposition rate. ${ }^{46,47}$ As for iron oxide, the deposition mechanism is similar to that of manganese oxide, starting from the oxidation of $\mathrm{Fe}^{2+}$ cations to $\mathrm{Fe}^{3+}$ and precipitation of the obtained iron hydroxide on the anode surface, but without the last oxidation step. ${ }^{17}$ Ammonium iron(II) sulfate was used as the common source material for $\mathrm{Fe}_{2} \mathrm{O}_{3}$ anodic deposition. In both cases, the mesopores might be formed from the scaffoldlike void spaces that originate between the aggregating metal hydroxide nanoparticles.

Unlike the conventional direct current (galvanostatic) deposition (DCD), in this work, we used pulse current deposition for the efficient coating of $\mathrm{MO}_{x}$ functional layers. Pulse deposition has been widely used in the industrial plating of nanocrystalline metals to improve deposits for several decades, while it is scarcely studied in the field of nanostructured metal oxides. Thus, the two electrodeposition techniques for optimizing the coating qualities in energy storage devices are worth comparing. The deposition conditions for DCD and PCD methods are similar, in both cases, the applied current density for the target electrodes was a fixed value of $47 \mu \mathrm{A}$ $\mathrm{cm}^{-2}$ ( $5 \mu \mathrm{A}$ per $0.105 \mathrm{~cm}^{-2}$ for the single electrode). The deposition time for $\mathrm{MnO}_{2}$ in the DCD mode was $5 \mathrm{~min}, 10 \mathrm{~min}$, $20 \mathrm{~min}$, and $40 \mathrm{~min}$; whereas the deposition time for $\mathrm{Fe}_{2} \mathrm{O}_{3}$ in the DCD mode was $10 \mathrm{~min}, 20 \mathrm{~min}, 40 \mathrm{~min}$, and $80 \mathrm{~min}$, separately. For pulse current deposition (PCD), a square-wave pulse signal was generated with a period of $5 \mathrm{~ms}$ and a duty ratio of 0.5 ( $5 \mathrm{~ms}$ 'on time' and $5 \mathrm{~ms}$ 'off time' for one duty cycle, as shown in Fig. S1†). Accordingly, the efficient deposition time for both $\mathrm{MnO}_{2}$ and $\mathrm{Fe}_{2} \mathrm{O}_{3}$ in the PCD mode was the same as those of the samples obtained in the DCD mode, while the total deposition time was double due to the extra 'off time'.

Fig. 2 and S2, $3 \uparrow$ show SEM images of $\mathrm{MnO}_{2}$ and $\mathrm{Fe}_{2} \mathrm{O}_{3}$ prepared by the DCD or PCD method at different coating times with post-treatment annealing. As shown in Fig. 2a and S2c, $\dagger$ $\mathrm{MnO}_{2}$ deposited by the galvanostatic approach exhibited a considerable number of cracks after coating for 20 minutes. Spalling and warping of the coated layers were clearly observed on a scale of hundreds of micrometers. The density of cracks and defects was even higher for a longer deposition time $(t=$ 40 min Fig. S2d $\dagger$ ), and the cracked films tended to peel off from the substrate, probably due to shrinkage stress of the thick layer. ${ }^{40}$ Similar issues of cracking and delamination were observed on the $\mathrm{Fe}_{2} \mathrm{O}_{3}$ film deposited by the galvanostatic method after 40 minutes of coating time (Fig. $2 \mathrm{~d}$ and S3a-d $\dagger$ ), with smaller warping cracks of around 2-5 micrometer long. In contrast, both $\mathrm{MnO}_{2}$ and $\mathrm{Fe}_{2} \mathrm{O}_{3}$ films prepared by PCD, using the same current density, revealed a uniform coating layer well adhering to the EG sublayer even after 40 minutes of deposition for $\mathrm{MnO}_{2}$ and 80 minutes of deposition for $\mathrm{Fe}_{2} \mathrm{O}_{3}$ (Fig. 2e, f and $\mathrm{S} 3 \mathrm{e}-\mathrm{h} \dagger$ ). The better film quality obtained by PCD with respect to the DCD current could be attributed to more efficient transport of ions achievable in the former tech- 

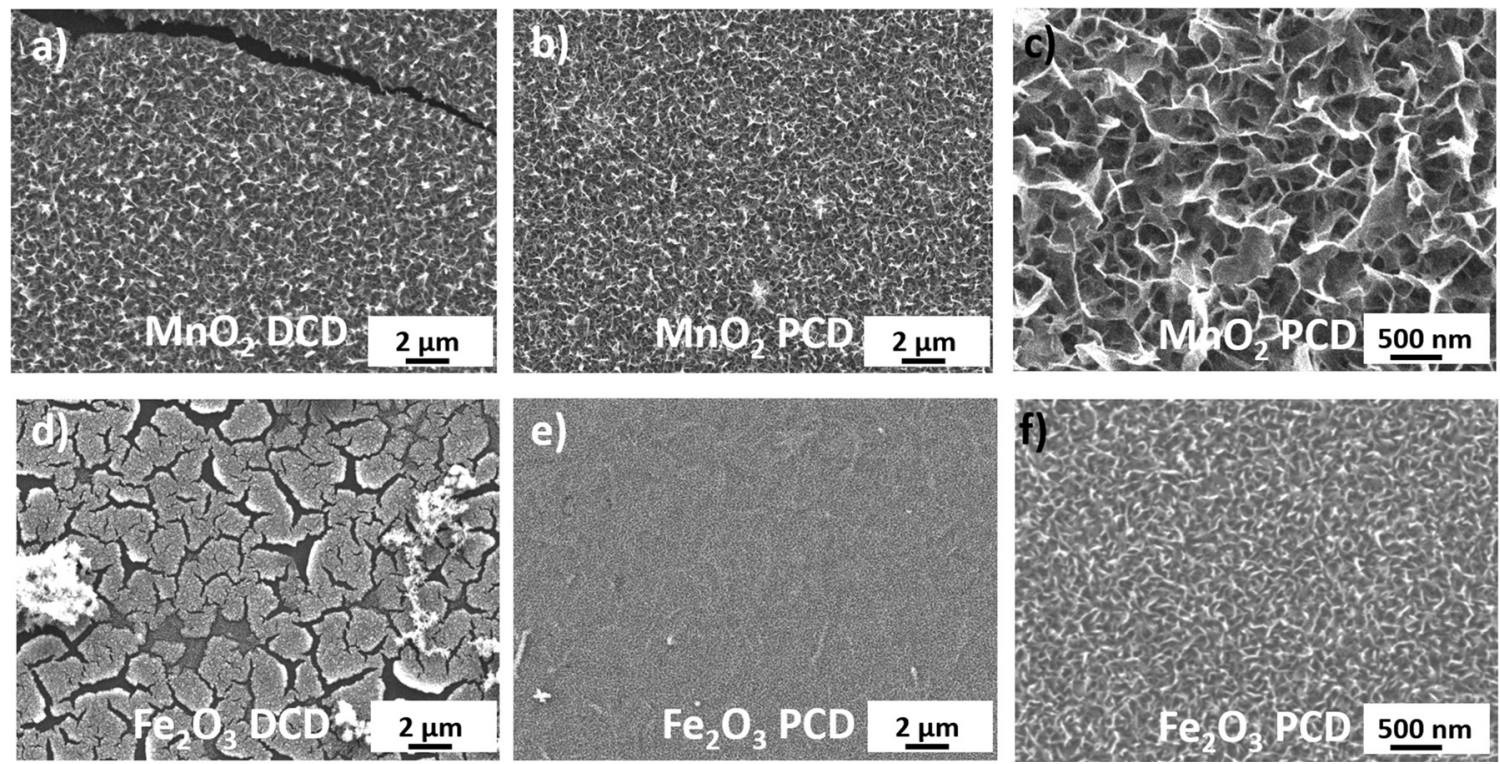

Fig. 2 SEM images of the $\mathrm{MnO}_{2}$ thin film coated on the EG pattern by (a) direct current deposition (DCD mode, $t=20$ min) and (b and c) pulse current deposition methods (PCD mode, $t=40 \mathrm{~min}$ ); $\mathrm{SEM}$ images of the $\mathrm{Fe}_{2} \mathrm{O}_{3}$ thin film coated on the EG pattern by (d) direct current deposition ( $D C D$ mode, $t=40 \mathrm{~min}$ ) and (e and $\mathrm{f}$ ) pulse current deposition methods ( $\mathrm{PCD}$ mode, $t=80 \mathrm{~min}$ ).

nique: the "on" time in PCD can generate a high instantaneous positive potential at the anode, and the huge overvoltage changes with ultra-short current pulses provide high localization of the Faradaic process with a small interelectrode gap on the anode side; ${ }^{48,49}$ meanwhile, the "off" time during the periodic pulse deposition gives manganese or iron ions sufficient replenishment time to diffuse from the bulk solution to the EG surface. ${ }^{9,50}$

Fig. 1 and $2 \mathrm{c}, \mathrm{f}$ show the typical surface morphology of $\mathrm{MnO}_{2}$ and $\mathrm{Fe}_{2} \mathrm{O}_{3}$ after 10 and 40 minutes of PCD, respectively. The two kinds of $\mathrm{MO}_{x}$ nanoflakes were well distributed on the microelectrode surface with mesoporous structures. The average pore size was on the order of $100 \mathrm{~nm}$ from $\mathrm{MnO}_{2}$ nanoflakes (Fig. 2c) with the film thickness on the order of $200 \mathrm{~nm}$, as estimated from SEM cross-section images (Fig. S4b†). The $\mathrm{MnO}_{2}$ layer thickness was tunable according to the deposition time: it increased from $150 \mathrm{~nm}$ to $300 \mathrm{~nm}$ by increasing deposition time from 5 to 20 minutes (Fig. S4a-c $\dagger$ ). In the case of $\mathrm{Fe}_{2} \mathrm{O}_{3}$, a more compact porous structure with closely packed small nanoflakes (average pore size of $50 \mathrm{~nm}$ ) and average film thickness of around $150 \mathrm{~nm}$ was observed $(t=40 \mathrm{~min}$, Fig. 2f and S4e†). The layer thickness of $\mathrm{Fe}_{2} \mathrm{O}_{3}$ increased from $90 \mathrm{~nm}$ to $230 \mathrm{~nm}$ by increasing deposition time from 20 to 80 minutes (Fig. S4d-f $\dagger$ ). These mesoporous structures from pulse current deposited $\mathrm{MnO}_{2}$ and $\mathrm{Fe}_{2} \mathrm{O}_{3}$ created high accessible surface area, which can provide effective ion transport pathways and consequently enhance the overall electrochemical performance of the final device. The XRD patterns of our $\mathrm{MO}_{x}$ samples (Fig. S5 $\dagger$ ) consist two broad peaks at $22.4^{\circ}$ and $26.7^{\circ}$, which primarily come from the (110) and (210) phase $^{51}$ of the polyimide substrate and the (002) phase of the graphene layer. ${ }^{52}$ Low intense signals at around $28.7^{\circ}$ for
$\mathrm{MnO}_{2}$ and $35.6^{\circ}$ for $\mathrm{Fe}_{2} \mathrm{O}_{3}$ also reveal the presence of very small oxide crystallites, possibly corresponding to pyrolusite $\beta-\mathrm{MnO}_{2}(110)$ and maghemite $\left.\gamma-\mathrm{Fe}_{2} \mathrm{O}_{3}(311)\right)^{53,54}$

We used Raman spectroscopy to compare bare EG, $\mathrm{MnO}_{2}-$ EG and $\mathrm{Fe}_{2} \mathrm{O}_{3}$-EG (Fig. 3a). The Raman spectra showed two distinct peaks at $1352 \mathrm{~cm}^{-1}$ and $1580 \mathrm{~cm}^{-1}$ for all three samples, attributed to the D peak (intervalley double resonance, usually from defect-related scattering) and the $\mathrm{G}$ peak (in-plane $\mathrm{E}_{2 \mathrm{~g}}$ optical phonon mode) from the defective EG layer. ${ }^{55,56}$ Another weak peak at $\sim 2700 \mathrm{~cm}^{-1}$ was due to the 2D peak of graphene (the second order of the D peak). The Raman spectrum at low wavenumbers revealed the scattering peaks of either $\mathrm{MnO}_{2}$ or $\mathrm{Fe}_{2} \mathrm{O}_{3}$ nanoflakes. The dominant peaks of $\mathrm{Fe}_{2} \mathrm{O}_{3}$ were at around 350 ( $\mathrm{T}_{2 \mathrm{~g}}$ mode), 511 ( $\mathrm{E}_{\mathrm{g}}$ mode), and $700 \mathrm{~cm}^{-1}$ ( $\mathrm{A}_{1 \mathrm{~g}}$ modes), ascribed to the maghemite phase of $\gamma-\mathrm{Fe}_{2} \mathrm{O}_{3} .{ }^{57}$ The Raman spectrum of the $\mathrm{MnO}_{2}$ film showed one main peak at $643 \mathrm{~cm}^{-1}$, which could be identified as $\mathrm{Mn}-\mathrm{O}$ stretching vibrations from the tetragonal $\beta-\mathrm{MnO}_{2}$ structure. ${ }^{58}$

The chemical composition of bare EG, $\mathrm{MnO}_{2}$-EG and $\mathrm{Fe}_{2} \mathrm{O}_{3}$ EG layers was confirmed by XPS analysis, showing C 1s, Mn $2 p$, Fe $2 p$ and $\mathrm{O} 1$ s core levels (see in Fig. $3 b-d$ and S6 $\dagger$ ). The C 1s spectra were measured for the bare EG sample; a sharp peak was observed at $284.6 \mathrm{eV}$ (Fig. $3 \mathrm{~b}$ ) due to the $\mathrm{sp}^{2} \mathrm{C}=\mathrm{C}$ bond and $\mathrm{sp}^{3} \mathrm{C}-\mathrm{C}$ bond, and other peaks at 286.2, 288.2, and $288.9 \mathrm{eV}$ were assigned to the $\mathrm{C}-\mathrm{OH} / \mathrm{C}-\mathrm{O}-\mathrm{C}, \mathrm{C}=\mathrm{O}$ and $\mathrm{O}-$ $\mathrm{C}=\mathrm{O}$ components, respectively. The existence of these oxygen functional groups was due to the printed EG ink, which can be attributed to the unavoidable oxidation of graphite during the anodic exfoliation process of EG sheets. Fig. 3c shows the Mn 2p spectrum from $\mathrm{MnO}_{2}$, which consists of two main peaks at 641.6 and $644.3 \mathrm{eV}$ for $\mathrm{Mn} 2 \mathrm{p}_{3 / 2}$, and one peak at $653.2 \mathrm{eV}$ for Mn $2 \mathrm{p}_{1 / 2}$. The energy separation between the Mn $2 \mathrm{p}_{3 / 2}$ and $\mathrm{Mn}$ 
a)

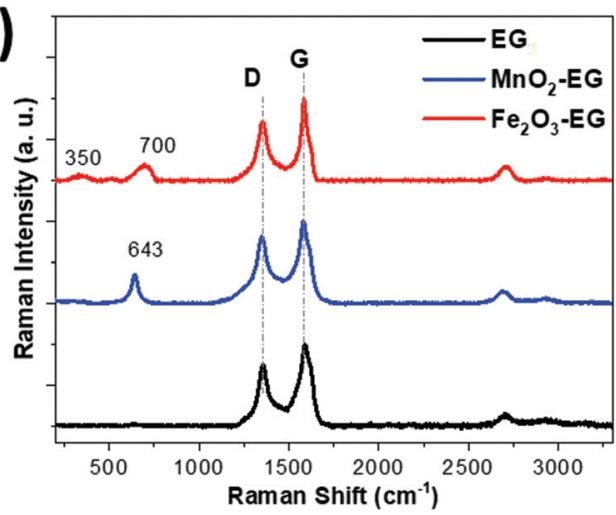

c)

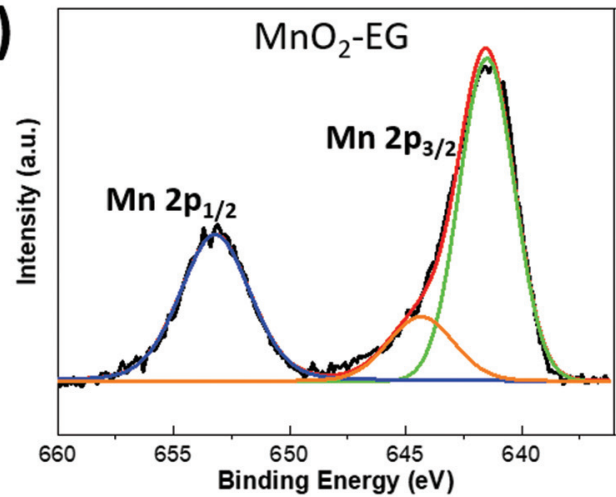

b)

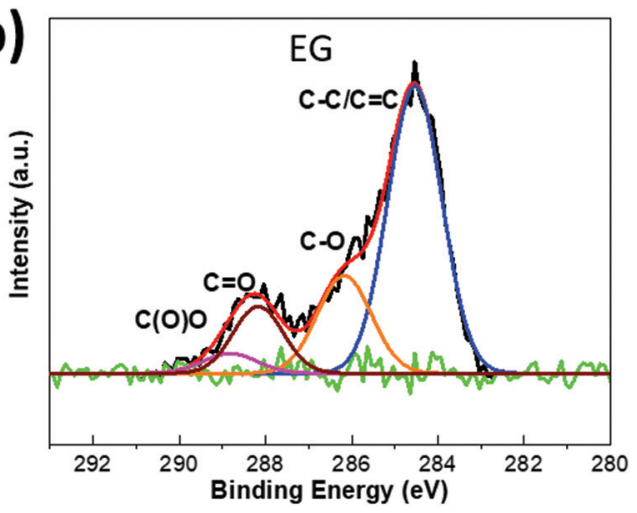

d)

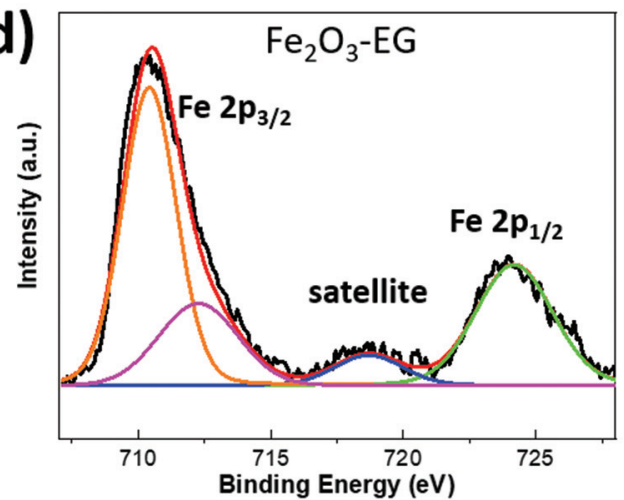

Fig. 3 (a) Raman spectrum of $E G, \mathrm{MnO}_{2}-\mathrm{EG}$ and $\mathrm{Fe}_{2} \mathrm{O}_{3}-\mathrm{EG}$ composites, and XPS spectrum of (b) $\mathrm{C} 1 \mathrm{~s}$, (c) Mn $2 \mathrm{p}$, and (d) Fe $2 p$ observed in bare $\mathrm{EG}$, $\mathrm{MnO}_{2}-\mathrm{EG}$, and $\mathrm{Fe}_{2} \mathrm{O}_{3}-\mathrm{EG}$ composites.

$2 \mathrm{p}_{1 / 2}$ is $11.6 \mathrm{eV}$, in agreement with previous reports on $\mathrm{MnO}_{2}$ materials. ${ }^{59}$ The $\mathrm{O} 1 \mathrm{~s}$ peak was deconvoluted in two main components: Mn-O-Mn component at $529.8 \mathrm{eV}$ and $\mathrm{Mn}-\mathrm{OH}$ component at $531.1 \mathrm{eV}$ (Fig. S6a †). The $-\mathrm{OH}$ bond might come from the adsorption of $\mathrm{O}_{2}$ and water molecules on the $\mathrm{MnO}_{2}$ surface. Meanwhile, Fig. 3d shows the chemical state of $\mathrm{Fe} 2 \mathrm{p}$, which was used to detect the presence of iron oxide. There were one main peak and a shoulder peak at 710.4 and 718.8 $\mathrm{eV}$ for Fe $2 \mathrm{p}_{3 / 2}$, and one peak at $724.2 \mathrm{eV}$ for $\mathrm{Fe} 2 \mathrm{p}_{1 / 2}$. The Fe $2 \mathrm{p}_{3 / 2}$ was also associated with a shake-up satellite around $7 \mathrm{eV}$ higher than the main peak, which is close to the experimental iron(III) oxide data reported in the literature. ${ }^{40,53}$ The $\mathrm{O} 1 \mathrm{~s}$ peak (see in Fig. S6b $\dagger$ ) was fitted using two main components: FeO-Fe component at $529.7 \mathrm{eV}$ and $\mathrm{Fe}-\mathrm{OH}$ component at 531.3 $\mathrm{eV}$, similar to the $\mathrm{MnO}_{2} \mathrm{O} 1 \mathrm{~s}$ result.

The detailed morphology and composition of $\mathrm{Fe}_{2} \mathrm{O}_{3}$ and $\mathrm{MnO}_{2}$ were further examined by TEM and EDS analysis at the nanoscale level. Fig. 4a and S7a † show the representative TEM images of crumpled $\mathrm{MnO}_{2}$ nanoflakes. High resolution TEM (HRTEM) image (Fig. 4a) revealed the relative lattice fringes with $d$ spacings of $0.31 \mathrm{~nm}$ and $0.16 \mathrm{~nm}$, which were corresponding to the (110) and (211) lattice plane of pyrolusite $\mathrm{MnO}_{2}$. In most cases, the orientation of $\mathrm{MnO}_{2}$ nanoflakes was random with no preferred direction, as evidenced by the broad diffraction rings from the fast Fourier transform (FFT) pattern (Fig. S7c †). ${ }^{10}$ Furthermore, the elemental composition of Mn, $\mathrm{O}$ and $\mathrm{Cu}$ was confirmed by energy dispersive X-ray spec- troscopy analysis (EDS) of the TEM copper grid of $\mathrm{MnO}_{2}$ flakes (Fig. S8a†). In the case of $\mathrm{Fe}_{2} \mathrm{O}_{3}$, a needle-like $\mathrm{Fe}_{2} \mathrm{O}_{3}$ nanoflake agglomerate was observed in TEM image (Fig. S7b $\dagger$ ) with an average thickness of 5-10 nm and a length of around $100 \mathrm{~nm}$, which is consistent with the SEM results. HRTEM images in Fig. $4 \mathrm{~b}$ and $\mathrm{S} 7 \mathrm{~b} \dagger$ show $\mathrm{Fe}_{2} \mathrm{O}_{3}$ nanoflakes randomly distributed on the TEM grid, which also explains the partial amorphous nature of the $\mathrm{Fe}_{2} \mathrm{O}_{3}$ film by XRD. The crystalline lattice of $\mathrm{Fe}_{2} \mathrm{O}_{3}$ sheets showed $d$ spacings of $0.30 \mathrm{~nm}, 0.25 \mathrm{~nm}$ and $0.17 \mathrm{~nm}$ corresponding to the (220) (311) and (422) lattice planes of the maghemite structure (Fig. S7d $\dagger$ ), which is consistent with the Raman and XRD results. The presence of Fe and $\mathrm{O}$ elements were confirmed by EDS analysis (Fig. S8b $\dagger$ ).

The electrochemical behaviour of $\mathrm{Fe}_{2} \mathrm{O}_{3}$ and $\mathrm{MnO}_{2}$ on EG MSCs were studied in a two-electrode configuration with a $1 \mathrm{M}$ $\mathrm{LiCl}$ aqueous electrolyte. We first used cyclic voltammetry (CV) to study what happens by coating only one of the two EG electrodes with $\mathrm{MO}_{x}$. $\mathrm{MnO}_{2}$ was coated by 10 minutes of PCD on the positive electrode, to obtain asymmetric $\mathrm{MnO}_{2} / \mathrm{EG}$ electrodes. On the other hand, $\mathrm{Fe}_{2} \mathrm{O}_{3}$ was coated by 40 minutes of pulse deposition on the negative electrode to obtain asymmetric EG/ $/ \mathrm{Fe}_{2} \mathrm{O}_{3}$ electrodes. To clarify, we refer to the different electrode couples as: positive electrode material/negative electrode material, in this order. These asymmetric samples were compared with pristine, symmetric EG electrodes.

There was no significant difference in the capacitance of $\mathrm{MnO}_{2} / \mathrm{EG} \mathrm{EG} / \mathrm{Fe}_{2} \mathrm{O}_{3}$ as compared to symmetric EG/EG devices, 

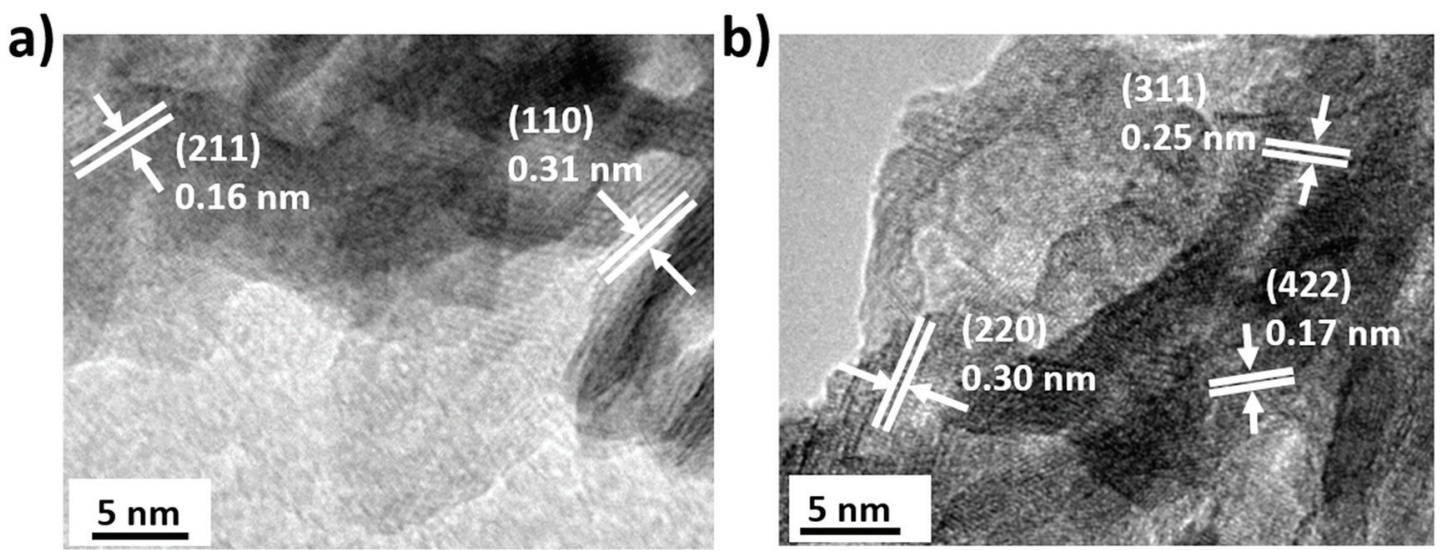

Fig. 4 High magnification TEM images of (a) $\mathrm{MnO}_{2}$ and (b) $\mathrm{Fe}_{2} \mathrm{O}_{3}$ nanoflakes.

as shown in Fig. S9. $\uparrow$ The areal capacitance values of $\mathrm{EG} / \mathrm{Fe}_{2} \mathrm{O}_{3}$ and $\mathrm{MnO}_{2} / \mathrm{EG}$ asymmetric MSCs were 47 and $52 \mu \mathrm{F} \mathrm{cm} \mathrm{cm}^{-2}$ at a scan rate of $100 \mathrm{mV} \mathrm{s}^{-1}$, these values are $c a .3$ times higher than the capacitance of initial EG MSCs $\left(\sim 15 \mu \mathrm{F} \mathrm{cm}{ }^{-2}\right)$. The small capacitance value of either bare $\mathrm{EG}$ or $\mathrm{MO}_{x} / \mathrm{EG}$ MSCs was attributed to the low EDLC capacitance of the bare EG electrode, and unbalanced charges between the EG and $\mathrm{MO}_{x}$ electrodes results in poor capacitor performance of the whole asymmetric device.

Then, we tried to study symmetric MSCs, where both electrodes were functionalized with the same material, affording either $\mathrm{Fe}_{2} \mathrm{O}_{3} / \mathrm{Fe}_{2} \mathrm{O}_{3}$ or $\mathrm{MnO}_{2} / \mathrm{MnO}_{2}$ electrode couples. $\mathrm{Fe}_{2} \mathrm{O}_{3}$ based symmetric MSCs were named $\mathrm{Fe}-1, \mathrm{Fe}-2$, and $\mathrm{Fe}-3$, according to their pulse deposition time of 20,40 and 80 minutes, respectively, whereas $\mathrm{MnO}_{2}$ based symmetric MSCs were named Mn-1, Mn-2, and Mn-3, according to their pulse deposition time of 5, 10 and 20 minutes (see in Fig. 5 and S10 $†$ ), respectively. We used different deposition times for Fe and $\mathrm{Mn}$ in order to achieve similar areal capacitance for devices for the two types of materials, as detailed below.

Fig. 5a, b and S11b $\uparrow$ show the CV curves of Fe-2 and Mn-2 devices. Both devices exhibited quasi-rectangular CV shapes at different scan rates. A slight distortion of the rectangular shape could evidence the pseudocapacitive behaviour of $\mathrm{MO}_{x}$. The pseudocapacitive behaviour of $\mathrm{Fe}_{2} \mathrm{O}_{3}$ could be explained by a fast and reversible faradaic reaction of the redox $\mathrm{Fe}^{3+} / \mathrm{Fe}^{2+}$ couple during the charge and discharge process. ${ }^{40,60}$ Similarly, the pseudocapacitive behaviour of $\mathrm{MnO}_{2}$ could be described by the redox transitions of interfacial oxidation species at various $\mathrm{Mn}$ oxidation states (e.g., $\left.\mathrm{Mn}^{3+} / \mathrm{Mn}^{4+}\right) \cdot{ }^{61}$ The areal capacitances of Fe-2 and Mn-2 were 253 and $244 \mu \mathrm{F} \mathrm{cm}^{-2}$ at a scan rate of $100 \mathrm{mV} \mathrm{s}^{-1}$, respectively, which is almost 15 times higher than that of the bare EG MSC device. Furthermore, the areal capacitances of $\mathrm{MO}_{x}$ based symmetric MSCs, deposited at various times, are plotted in Fig. $5 \mathrm{c}$ and d. In all cases, the areal capacitance increased with the PCD coating time. All symmetric $\mathrm{MO}_{x}$-MSCs showed much higher areal capacitances as compared to that of the bare EG one. By using different deposition times, we could achieve matchable capacity values for Fe-1/Mn-1, Fe-2/Mn-2, and Fe-3/Mn-3 devices (see in Fig. S11 $\dagger$ ). The above results help us to rationally design asymmetric MSC devices with charge balancing between the positive $\mathrm{MnO}_{2}$ electrode and the negative $\mathrm{Fe}_{2} \mathrm{O}_{3}$ electrode.

After matching the loading amount of the positive and negative electrode, we produced asymmetric MSC device coating $\mathrm{MnO}_{2}$ for 10 min on the positive electrode and $\mathrm{Fe}_{2} \mathrm{O}_{3}$ for $40 \mathrm{~min}$ on the negative electrode $\mathrm{MnO}_{2} / \mathrm{Fe}_{2} \mathrm{O}_{3}$. This time we used the LiCl/PVA gel electrolyte instead of the liquid electrolyte, simply because the PVA based polymer electrode features a high water absorbing and holding capacity, easy handling without the risk of leakage of the liquid electrolyte, which is suitable for flexible A-MSC devices and on-chip integration.

The asymmetric $\mathrm{MnO}_{2} / \mathrm{Fe}_{2} \mathrm{O}_{3}$ sample (Fe-Mn) was tested in an operating potential window range from 0 to $1.6 \mathrm{~V}$, according to previous studies on symmetric metal oxide devices. ${ }^{60}$ Fig. 6a shows the CV curves of Fe-Mn-A-MSC obtained at different scan rates, from $5 \mathrm{mV} \mathrm{s}^{-1}$ to $100 \mathrm{mV} \mathrm{s}^{-1}$. A nearly rectangular CV shape at different scan rates indicates fast and reversible redox reactions of both electrodes, $\mathrm{MnO}_{2}$ and $\mathrm{Fe}_{2} \mathrm{O}_{3}$. The maximum areal capacitance achieved from Fe-Mn $(1534 \mu \mathrm{F}$ $\mathrm{cm}^{-2}$ at $5 \mathrm{mV} \mathrm{s}^{-1}$ ) is much higher than that from the bare EG device $\left(39 \mu \mathrm{F} \mathrm{cm}^{-2}\right.$ at $\left.5 \mathrm{mV} \mathrm{s}^{-1}\right)$ in the PVA/LiCl gel electrolyte by a factor of 40 (see in Fig. S12 $\dagger$ ). Our result obtained for a PCD device is also superior to that for DCD based Fe-Mn A-MSC prepared with the same deposition time (the maximum areal capacitance of DCD based device is $348 \mu \mathrm{F} \mathrm{cm}{ }^{-2}$ at $5 \mathrm{mV}$ $\mathrm{s}^{-1}$, Fig. $\mathrm{S} 13 \dagger$ ), further confirming the advantage of pulse current deposition in high performance MSC devices. Moreover, the galvanostatic charge-discharge (GCD) measurements under different current densities from 5 to $50 \mu \mathrm{A} \mathrm{cm}{ }^{2}$ (Fig. 6b) shows a small deviation from the triangular shape and relatively symmetric shape of GCD curves, indicating good electrochemical performance of our metal oxide electrodes, in agreement with previous CV results. Fig. $6 \mathrm{c}$ presents the rate performance of the $\mathrm{Fe}-\mathrm{Mn}$ device at different current densities. A high stack capacitance of $110.6 \mathrm{~F} \mathrm{~cm}^{-3}$ was achieved at a current density of $5 \mu \mathrm{A} \mathrm{cm}{ }^{-2}$, which significantly exceeds that of the previously reported graphene-based devices (e.g. 
a)

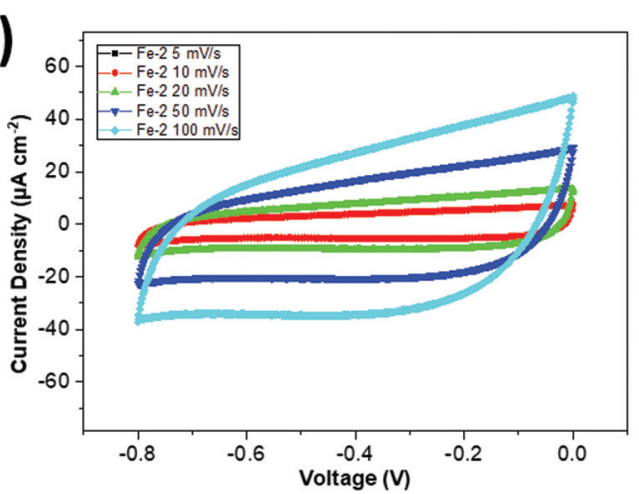

c)

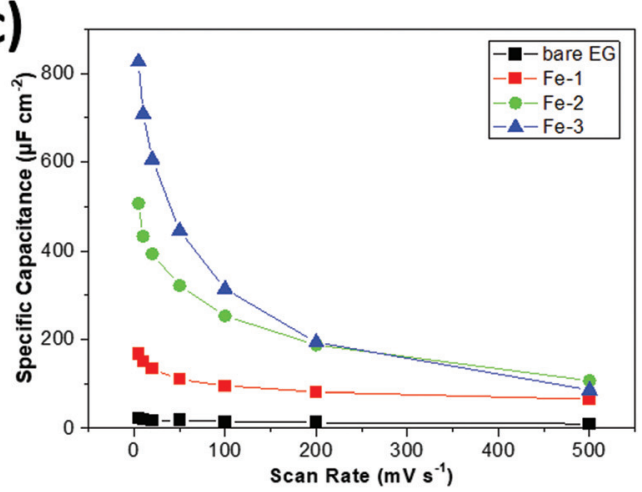

b)
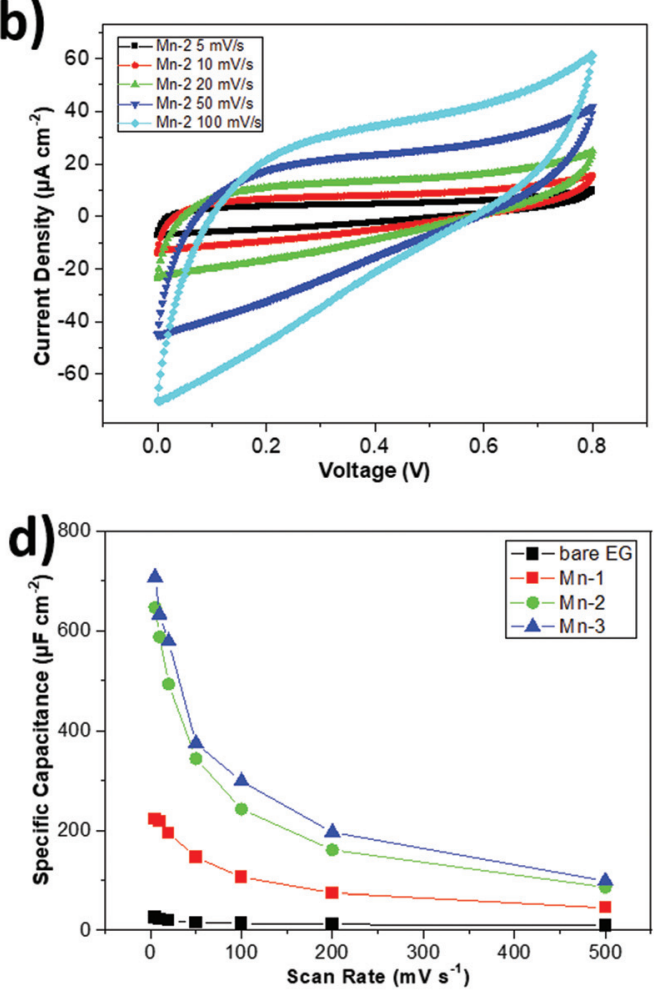

Fig. 5 Electrochemical performance of symmetric MSCs. CV curves of (a) Fe-MSC-2 and (b) Mn-MSC-2 symmetric devices at different scan rates; specific areal capacitances of (c) Fe-MSCs and (d) Mn-MSCs with different loading amounts at different scan rates.
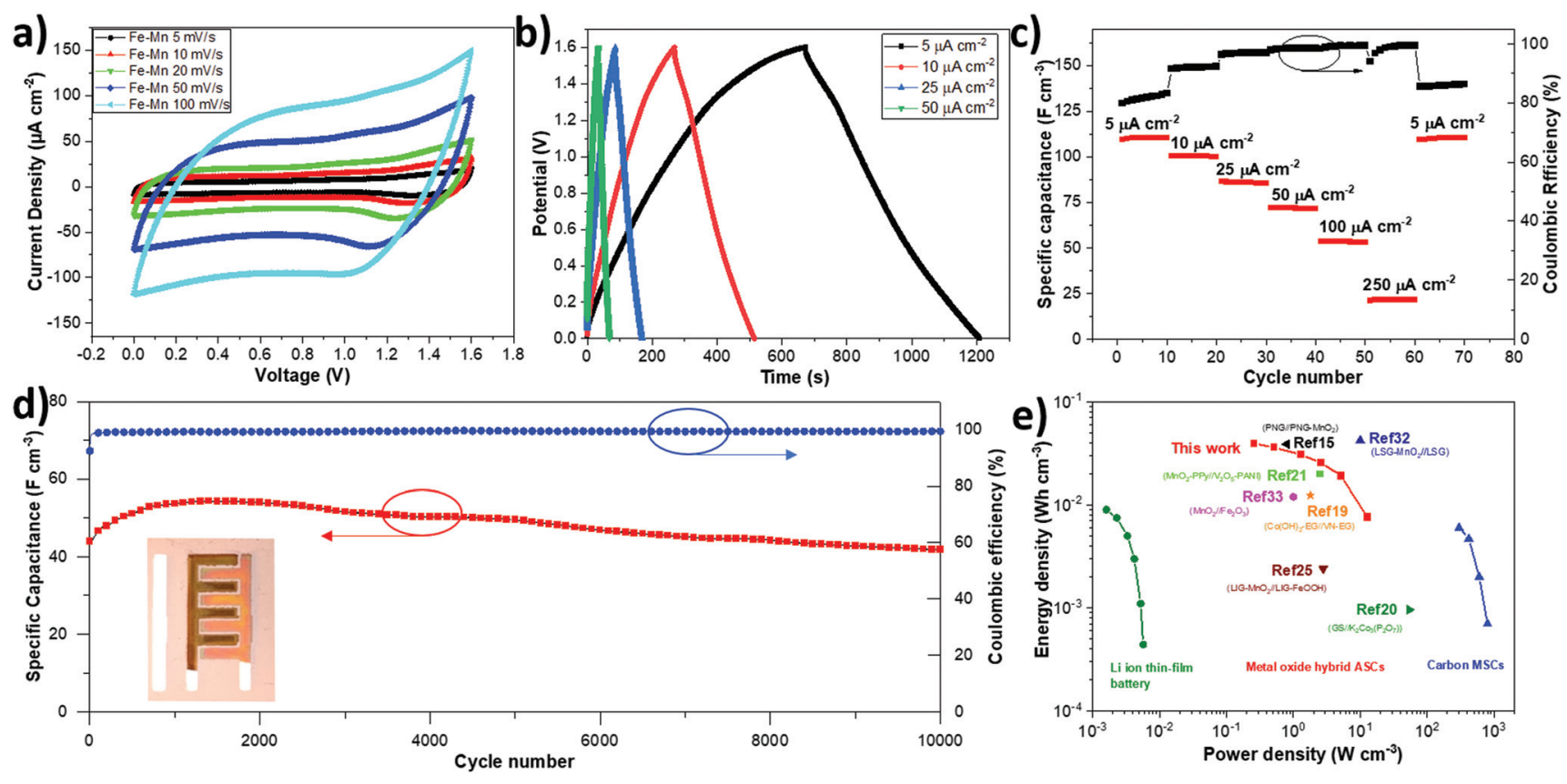

Fig. 6 Electrochemical performance of asymmetric Fe-Mn A-MSC prepared by PCD in LiCl/PVA electrodes. (a) CV curves of Fe-Mn at different scan rates; (b) charge-discharge curves of Fe-Mn at different current densities; (c) rate capability of Fe-Mn at different current densities; (d) longterm cycling stability of Fe-Mn at a current density of $100 \mu \mathrm{A} \mathrm{cm}^{-2}$; (e) Ragone plot of specific volumetric energy density and power density for FeMn compared with other microscale energy-storage devices. 
1.3 $\mathrm{F} \mathrm{cm}^{-3}$ for onion-like graphene based MSCs and $3.1 \mathrm{~F}$ $\mathrm{cm}^{-3}$ for laser-written graphene oxide MSCs), ${ }^{62,63}$ and also superior to others state-of-the-art transition metal oxide based A-MSCs, e.g., $\mathrm{MnO}_{2} / / \mathrm{Fe}_{2} \mathrm{O}_{3}$ A-MSCs on $\mathrm{Cr} / \mathrm{Ni}$ patterns $(60 \mathrm{~F}$ $\mathrm{cm}^{-3}$ ), PNG- $\mathrm{MnO}_{2} / / \mathrm{PNG}$ on a plasma reduced and nitrogendoped graphene oxide substrate (38.1 $\left.\mathrm{F} \quad \mathrm{cm}^{-3}\right)$, and NPG-MnO ${ }_{2} / / \mathrm{NPG}-P$ py on a nano-porous gold substrate $(45.3 \mathrm{~F}$ $\left.\mathrm{cm}^{-3}\right) .{ }^{15,32,38}$ To demonstrate the device stability of our asymmetric supercapacitor, we also performed long-term cycling of Fe-Mn A-MSC by GCD at $100 \mu \mathrm{A} \mathrm{cm}^{-2}$. Interestingly, our device retained about $95.7 \%$ of the initial value with a high coulombic efficiency (99.3\%) after 10000 cycles, as shown in Fig. 6d. Furthermore, the bending test was performed under different angles with $\mathrm{CV}$ scan at $100 \mathrm{mV} \mathrm{s}^{-1}$ (see in Fig. S14†). The capacitance of the Fe-Mn device maintained almost the same value after bending at $c a .90^{\circ}$ and $180^{\circ}$, showing the potential applicability of this A-MSC as a flexible supercapacitor device.

Finally, the volumetric energy and power density of Fe-Mn were compared with the state-of-the-art performance metrics obtained from the literature (Fig. 6e). The Fe-Mn A-MSC device delivers a maximum energy density of $39 \mathrm{~mW} \mathrm{~h} \mathrm{~cm} \mathrm{~cm}^{-3}$ (corresponding power density of $259 \mathrm{~mW} \mathrm{~cm}^{-3}$ ) and a maximum power density $12.9 \mathrm{~W} \mathrm{~cm}^{-3}$ (corresponding energy density of $7.6 \mathrm{~mW} \mathrm{~h} \mathrm{~cm}^{-3}$ ). The energy density value is much higher than those of typical carbon-based micro-supercapacitors, and comparable with those of a Li thin-film battery

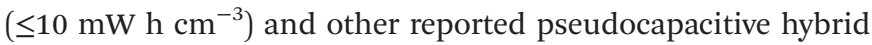
A-MSCs (Table S1†) such as LIG- $\mathrm{MnO}_{2} / / \mathrm{LIG}-\mathrm{FeOOH}(2.4 \mathrm{~mW} \mathrm{~h}$ $\left.\mathrm{cm}^{-3}\right), \mathrm{MnO}_{2} / / \mathrm{Fe}_{2} \mathrm{O}_{3}\left(12 \mathrm{~mW} \mathrm{~h} \mathrm{~cm}{ }^{-3}\right), \mathrm{Co}(\mathrm{OH})_{2}$-EG//VN-EG (12.4 $\mathrm{mW} \mathrm{h} \mathrm{cm}{ }^{-3}$ ), and PNG//PNG-MnO $\left(38.1 \mathrm{~mW} \mathrm{~h} \mathrm{~cm}^{-3}\right.$ ) micro-supercapacitors. ${ }^{15,19,30,38,64}$

\section{Conclusions}

In summary, pulse current deposition has been demonstrated as a facile and highly efficient electrochemical approach for the fabrication of high-performance planar asymmetric MSCs. Crackfree $\mathrm{MnO}_{2}$ and $\mathrm{Fe}_{2} \mathrm{O}_{3}$ mesoporous nanoflakes were uniformly electrodeposited on inkjet-printed graphene micropatterns as positive and negative A-MSC electrodes respectively. The fabricated A-MSCs exhibit simultaneously increased volumetric capacitance and working voltage window, thus leading to significantly higher energy density than other MSCs previously reported in the literature. The low-cost of electrodeposition techniques facilitate upscaling $\mathrm{MO}_{x}$ coating from the laboratory level to large scale industrial production. The versatility of such an electrodeposition approach paves the way towards the fabrication of other metal oxide structures, in search for synergies between metal cations and enhanced electrochemical properties.

\section{Experimental section}

\section{Electrochemical exfoliation of graphene}

The EG was produced according to the procedure described in our previous publication. ${ }^{23}$ Briefly, two pieces of graphite foil
(Alfa Aesar, $0.13 \mathrm{~mm}$ thick, product number: 43078) were inserted into $0.1 \mathrm{M}\left(\mathrm{NH}_{4}\right)_{2} \mathrm{SO}_{4}$ aqueous electrolyte solution as the cathode and anode (at a distance of $2 \mathrm{~cm}$ ), respectively, and biased at a DC voltage of $10 \mathrm{~V}$ for exfoliation. The obtained graphite powder was collected and the rinsed powder was dispersed in DMF at a concentration of about $2 \mathrm{mg} \mathrm{mL}^{-1}$ by ultrasonication for $10 \mathrm{~min}$.

\section{Graphene ink formulation}

The centrifugation-assisted solvent exchange technique was used to formulate EG ink. First, $\sim 40 \mathrm{~mL}$ EG/DMF dispersion was centrifuged at $3000 \mathrm{rpm}$ for $15 \mathrm{~min}$ to remove the largest particles. Then the supernatant was harvested and centrifuged again at $10500 \mathrm{rpm}$ for $15 \mathrm{~min}$ to separate EG from DMF. After DMF was removed, $16 \mathrm{~mL}$ of the mixed solvent of cyclohexanone and terpineol (with a volume ratio of $3: 1$ ) and $320 \mathrm{mg}$ of ethyl cellulose (viscosity $4 \mathrm{cP}$ for $5 \mathrm{w} / \mathrm{v} \%$ in $80: 20$ toluene : ethanol, Sigma-Aldrich, product number: 200646) were added to disperse the sedimented EG and sonicated for $30 \mathrm{~min}$. Finally, the EEG ink was centrifuged at $2000 \mathrm{rpm}$ for $3 \mathrm{~min}$ to further remove big particles. The final ink concentration was about $2.3 \mathrm{mg} \mathrm{mL}^{-1}$.

\section{Fabrication of planar EG-MSCs}

EG ink was printed using a commercial piezoelectric Dimatix Materials Printer (DMP 2800, Dimatix-Fujifilm Inc.) equipped with a $10 \mathrm{pL}$ cartridge (DMC-11610). First, EG inks are printed at the drop spacing of $25 \mu \mathrm{m}$ and substrate temperature of $45{ }^{\circ} \mathrm{C}$ on different substrates to form the electrodes for MSCs. Afterward, the samples were annealed on a hot plate in air for 1-2 $\mathrm{h}$ at temperatures of around $380^{\circ} \mathrm{C}$ for the Kapton substrate.

\section{Selective deposition of the $\mathrm{MnO}_{2}$ or $\mathrm{Fe}_{2} \mathrm{O}_{3}$ thin film on EG electrodes}

A polydimethylsiloxane (PDMS) mask was fixed on the top of MSC along with an electrochemical setup composed of a twoelectrode cell: a Pt wire as the counter electrode and the target substrate as the working electrode. For $\mathrm{MnO}_{2}$ coating, few droplets of $10 \mathrm{mM} \mathrm{Mn}\left(\mathrm{COOCH}_{3}\right)_{2}$ and $40 \mathrm{mM} \mathrm{NaCOOCH} \mathrm{m}_{3}$ solution in water were deposited inside the mask as the electrolyte for $\mathrm{MnO}_{x}$ deposition. For $\mathrm{Fe}_{2} \mathrm{O}_{3}$ coating, few droplets of $10 \mathrm{mM}\left(\mathrm{NH}_{4}\right)_{2} \mathrm{Fe}\left(\mathrm{SO}_{4}\right)_{2}$ and $40 \mathrm{mM} \mathrm{NaCOOCH}{ }_{3}$ solution were used as the electrolyte. Galvanostatic direct current electrodeposition was performed under a positive bias to the target electrode, maintaining a current density of $47 \mu \mathrm{A} \mathrm{cm}{ }^{-2}$ to coat $\mathrm{MnO}_{x}$ or $\mathrm{FeOOH}$ films on EG-based MSC electrodes with time from 5 to $80 \mathrm{~min}$. Pulse current deposition was conducted using a square-wave pulse current of $47 \mu \mathrm{A} \mathrm{cm} \mathrm{cm}^{-2}(5 \mu \mathrm{A}$ current on the $0.105 \mathrm{~cm}^{-2}$ single electrode area, as shown in Fig. S1b $\dagger$ ) with a period of $5 \mathrm{~ms}$ and a duty ratio of 0.5 with the time from 5 to $80 \mathrm{~min}$. A function generator (Tenma 72-14111) was used for the generation of the wave function signal, and Keithley 2450 was connected with the wave generator as the power source. After electrochemical deposition, the composites were sequentially washed with DI water and dried under a gentle flow of nitrogen gas. Then, the MSCs were annealed at $300{ }^{\circ} \mathrm{C}$ under ambient air conditions. 


\section{Electrochemical characterization}

All the electrochemical properties of the fully printed MSCs were characterized using a two-electrode configuration Biologic SP-300 potentiostat (for CV profiles). The areal capacitance $C_{\mathrm{A}}$ was calculated either from the CV profiles or the GCD curves. For the CV profiles, $C_{\mathrm{A}, \mathrm{CV}}=\int_{0}^{\Delta V}\left(I_{\mathrm{C}}-I_{\mathrm{D}}\right) \mathrm{d} V /(2 A v \Delta V)$, where $I_{\mathrm{C}}$ and $I_{\mathrm{D}}$ are the charging and discharging currents, respectively, $\Delta V$ is the voltage window, $A$ is the active area of the metal oxide film, and $\nu$ is the scan rate. The total device area was calculated according to the pattern size of active materials $\left(A=(2.3 \times 0.7 \times 4+6 \times 0.7) \times 2=21 \mathrm{~mm}^{2}=0.21 \mathrm{~cm}^{2}\right.$, see in Fig. S1b $\dagger$ ). For the GCD curves, $C_{\mathrm{A}, \mathrm{GDC}}=I \Delta V / A \Delta t$ where $I$ is the discharging current and $\Delta_{t}$ is the discharging time. All the areal energy density is calculated as $E_{\mathrm{A}}=0.5 C_{\mathrm{A}, \mathrm{CV}} \Delta V^{2}$, and the areal power density is $P_{\mathrm{A}}=E_{\mathrm{A}} / t=\nu E_{\mathrm{A}} / \Delta V$ with $t=\Delta V / \nu$ being the discharging time. The volumetric energy (power) density is calculated by dividing $E_{\mathrm{A}}(\mathrm{PA})$ by the average MOx layer thickness $(T)$ measured from our SEM cross-sections $(T=$ $(151+197) / 2=174 \mathrm{~nm})$.

\section{Materials characterization}

The surface morphology of the $\mathrm{MnO}_{2}$ or $\mathrm{Fe} 2 \mathrm{O}_{3}$ thin film was monitored by field emission scanning electron microscopy (JEOL JSM-7800F Prime), under an accelerating voltage of $8 \mathrm{kV}$. Transmission electron microscopy (FEI Tecnai T20, $200 \mathrm{kV}$ ) was used to characterize the metal oxide crystalline structures. Raman spectroscopy was performed using a WITec alpha300 $\mathrm{R}$, with a $532 \mathrm{~nm}$ laser line and a laser spot size of $300 \mathrm{~nm}$. XRD measurements were performed on a Bruker D8 Advance diffractometer at $40 \mathrm{kV}$ and $40 \mathrm{~mA}$ with $\mathrm{Cu} \mathrm{K \alpha}$ radiation $(\lambda=$ $0.1542 \mathrm{~nm}$ ). The chemical configuration was measured using a VersaProbe III X-ray photoelectron spectroscope, in an ultrahigh vacuum (UHV) apparatus (base pressure $1 \times 10^{-10} \mathrm{mbar}$ ) using a non-monochromatic $\mathrm{Mg}$-Ko excitation source.

\section{Conflicts of interest}

The authors declare no competing financial interest.

\section{Acknowledgements}

The research leading to these results has received funding from the European Union's Horizon 2020 research and innovation programme (grant agreement no. 696656 Graphene Flagship), the EC Marie-Curie ITN-iSwitch (GA no. 642196), the Swedish Research Council Formas (grant no. 2016-00496), and the ÅForsk Foundation (grant no. 17-352).

\section{References}

1 J. B. Goodenough and K. S. Park, J. Am. Chem. Soc., 2013, 135, 1167-1176.
2 C. K. Chan, H. L. Peng, G. Liu, K. McIlwrath, X. F. Zhang, R. A. Huggins and Y. Cui, Nat. Nanotechnol., 2008, 3, 31-35.

3 M. Salanne, B. Rotenberg, K. Naoi, K. Kaneko, P. L. Taberna, C. P. Grey, B. Dunn and P. Simon, Nat. Energy, 2016, 1, 16070.

4 M. Beidaghi and Y. Gogotsi, Energy Environ. Sci., 2014, 7, 867-884.

5 Z. S. Wu, K. Parvez, X. L. Feng and K. Mullen, Nat. Commun., 2013, 4, 2487.

6 J. T. Li, F. Ye, S. Vaziri, M. Muhammed, M. C. Lemme and M. Ostling, Adv. Mater., 2013, 25, 3985-3992.

7 C. H. An, Y. Zhang, H. N. Guo and Y. J. Wang, Nanoscale Adv., 2019, 1, 4644-4658.

8 N. Choudhary, C. Li, J. Moore, N. Nagaiah, L. Zhai, Y. Jung and J. Thomas, Adv. Mater., 2017, 29, 1605336.

9 S. H. Lee, H. Lee, M. S. Cho, J. D. Nam and Y. Lee, J. Mater. Chem. A, 2013, 1, 14606-14611.

10 T. Nguyen, M. Boudard, M. J. Carmezim and M. F. Montemor, Electrochim. Acta, 2016, 202, 166-174.

11 J. Jung, J. R. Jeong, J. Lee, S. H. Lee, S. Y. Kim, M. J. Kim, J. Nah and M. H. Lee, NPG Asia Mater., 2020, 12, 50.

12 W. T. Wang, L. S. Lu, Y. X. Xie, W. Yuan, Z. P. Wan, Y. Tang and K. S. Teh, Adv. Mater. Technol., 2020, 5, 1900903.

13 D. Kim, J. Yun, G. Lee and J. S. Ha, Nanoscale, 2014, 6, 12034-12041.

14 S. Kaipannan and S. Marappan, Sci. Rep., 2019, 9, 1104.

15 L. Z. Zhang, Z. Q. Chen, S. H. Zheng, S. Qin, J. M. Wang, C. Chen, D. Liu, L. F. Wang, G. L. Yang, Y. Y. Su, Z. S. Wu, X. H. Bao, J. Razal and W. W. Lei, J. Mater. Chem. A, 2019, 7, 14328-14336.

16 X. H. Lu, Y. X. Zeng, M. H. Yu, T. Zhai, C. L. Liang, S. L. Xie, M. S. Balogun and Y. X. Tong, Adv. Mater., 2014, 26, 3148-3155.

17 Z. Y. Xia, D. Wei, E. Anitowska, V. Bellani, L. Ortolani, V. Morandi, M. Gazzano, A. Zanelli, S. Borini and V. Palermo, Carbon, 2015, 84, 254-262.

18 W. Tang, L. L. Liu, S. Tian, L. Li, Y. B. Yue, Y. P. Wu and K. Zhu, Chem. Commun., 2011, 47, 10058-10060.

19 S. Wang, Z. S. Wu, F. Zhou, X. Y. Shi, S. H. Zheng, J. Q. Qin, H. Xiao, C. L. Sun and X. H. Bao, npj 2D Mater. Appl., 2018, $2,7$.

20 H. Pang, Y. Z. Zhang, W. Y. Lai, Z. Hu and W. Huang, Nano Energy, 2015, 15, 303-312.

21 Y. Yue, Z. C. Yang, N. S. Liu, W. J. Liu, H. Zhang, Y. A. Ma, C. X. Yang, J. Su, L. Y. Li, F. Long, Z. G. Zou and Y. H. Gao, ACS Nano, 2016, 10, 11249-11257.

22 R. S. Guo, J. T. Chen, B. J. Yang, L. Y. Liu, L. J. Su, B. S. Shen and X. B. Yan, Adv. Funct. Mater., 2017, 27, 1702394.

23 J. T. Li, S. S. Delekta, P. P. Zhang, S. Yang, M. R. Lohe, X. D. Zhuang, X. L. Feng and M. Ostling, ACS Nano, 2017, 11, 8249-8256.

24 J. Q. Xie, Y. Q. Ji, J. H. Kang, J. L. Sheng, D. S. Mao, X. Z. Fu, R. Sun and C. P. Wong, Energy Environ. Sci., 2019, 12, 194-205. 
25 C. H. Wang, X. Li, Y. Zhao, M. N. Banis, J. W. Liang, X. N. Li, Y. P. Sun, K. R. Adair, Q. Sun, Y. L. Liu, F. P. Zhao, S. X. Deng, X. T. Lin, R. Y. Li, Y. F. Hu, T. K. Sham, H. Huang, L. Zhang, R. Yang, S. G. Lu and X. L. Sun, Small Methods, 2019, 3, 1900261.

26 S. Bellani, E. Petroni, A. E. D. Castillo, N. Curreli, B. Martin-Garcia, R. Oropesa-Nunez, M. Prato and F. Bonaccorso, Adv. Funct. Mater., 2019, 29, 1807659.

27 J. H. Zhang, G. X. Zhang, T. Zhou and S. H. Sun, Adv. Funct. Mater., 2020, 30, 1910000.

28 H. P. Li and J. J. Liang, Adv. Mater., 2020, 32, 1805864.

29 S. S. Delekta, M. M. Laurila, M. Mantysalo and J. T. Li, Nano-Micro Lett., 2020, 12, 40.

30 L. Li, J. B. Zhang, Z. W. Peng, Y. L. Li, C. T. Gao, Y. S. Ji, R. Q. Ye, N. D. Kim, Q. F. Zhong, Y. Yang, H. L. Fei, G. D. Ruan and J. M. Tour, Adv. Mater., 2016, 28, 838845.

31 L. M. Sun, X. H. Wang, W. W. Liu, K. Zhang, J. P. Zou and Q. Zhang, J. Power Sources, 2016, 315, 1-8.

32 C. Zhang, J. Xiao, L. H. Qian, S. L. Yuan, S. Wang and P. X. Lei, J. Mater. Chem. A, 2016, 4, 9502-9510.

33 A. Liscio, E. Orgiu, J. M. Mativetsky, V. Palermo and P. Samori, Adv. Mater., 2010, 22, 5018-5023.

34 J. M. Mativetsky, E. Treossi, E. Orgiu, M. Melucci, G. P. Veronese, P. Samori and V. Palermo, J. Am. Chem. Soc., 2010, 132, 14130-14136.

35 J. M. Mativetsky, A. Liscio, E. Treossi, E. Orgiu, A. Zanelli, P. Samori and V. Palermo, J. Am. Chem. Soc., 2011, 133, 14320-14326.

36 G. A. M. Ali, M. M. Yusoff, Y. H. Ng, H. N. Lim and K. F. Chong, Curr. Appl. Phys., 2015, 15, 1143-1147.

37 M. F. El-Kady, M. Ihns, M. Li, J. Y. Hwang, M. F. Mousavi, L. Chaney, A. T. Lech and R. B. Kaner, Proc. Natl. Acad. Sci. U. S. A., 2015, 112, 4233-4238.

38 Z. H. Liu, X. C. Tian, X. Xu, L. He, M. Y. Yan, C. H. Han, Y. Li, W. Yang and L. Q. Mai, Nano Res., 2017, 10, 24712481.

39 T. Nguyen, M. Boudard, M. J. Carmezim and M. F. Montemor, Sci. Rep., 2017, 7, 39980.

40 Z. Y. Xia, M. Christian, C. Arbizzani, V. Morandi, M. Gazzano, V. Quintano, A. Kovtun and V. Palermo, Nanoscale, 2019, 11, 5265-5273.

41 Z. H. Yan, H. M. Sun, X. Chen, H. H. Liu, Y. R. Zhao, H. X. Li, W. Xie, F. Y. Cheng and J. Chen, Nat. Commun., 2018, 9, 2373.

42 A. Biswal, P. K. Panda, A. N. Acharya, S. Mohapatra, N. Swain, B. C. Tripathy, Z. T. Jiang and M. M. Sundaram, ACS Omega, 2020, 5, 3405-3417.

43 H. Adelkhani, M. Ghaemi and S. M. Jafari, J. Power Sources, 2007, 163, 1091-1104.

44 J. Hu, Y. F. Zhu, Q. Liu, Y. B. Gao, R. G. Du and C. J. Lin, J. Electrochem. Soc., 2015, 162, C161-C166.
45 G. H. A. Therese and P. V. Kamath, Chem. Mater., 2000, 12, 1195-1204.

46 Y. S. Chen, C. C. $\mathrm{Hu}$ and Y. T. Wu, J. Solid State Electrochem., 2004, 8, 467-473.

47 J. N. Broughton and M. J. Brett, Electrochim. Acta, 2005, 50, 4814-4819.

48 N. H. Phan, M. Schwartz and K. Nobe, Electrochim. Acta, 1994, 39, 449-453.

49 J.-C. Puippe, F. Leaman and E. American and S. Surface Finishers, Theory and practice of pulse plating, American Electroplaters and Surface Finishers Society, Orlando, Fla., 1986.

50 S. Daryadel, A. Behroozfar, S. R. Morsali, S. Moreno, M. Baniasadi, J. Bykova, R. A. Bernal and M. MinaryJolandan, Nano Lett., 2018, 18, 208-214.

51 S. S. Dong, W. Z. Shao, L. Yang, H. J. Ye and L. Zhen, RSC Adv., 2018, 8, 28152-28160.

52 Z. Y. Xia, S. Pezzini, E. Treossi, G. Giambastiani, F. Corticelli, V. Morandi, A. Zanelli, V. Bellani and V. Palermo, Adv. Funct. Mater., 2013, 23, 4684-4693.

53 I. Banerjee, Y. B. Khollam, C. Balasubramanian, R. Pasricha, P. P. Bakare, K. R. Patil, A. K. Das and S. V. Bhoraskar, Scr. Mater., 2006, 54, 1235-1240.

54 J. Xiao, P. Liu, Y. Liang, H. B. Li and G. W. Yang, J. Appl. Phys., 2013, 114, 073513.

55 Z. Y. Xia, F. Leonardi, M. Gobbi, Y. Liu, V. Bellani, A. Liscio, A. Kovtun, R. J. Li, X. L. Feng, E. Orgiu, P. Samori, E. Treossi and V. Palermo, ACS Nano, 2016, 10, 7125-7134.

56 Z. Y. Xia, G. Maccaferri, C. Zanardi, M. Christian, L. Ortolani, V. Morandi, V. Bellani, A. Kovtun, S. Dell'Elce, A. Candini, A. Liscio and V. Palermo, J. Phys. Chem. C, 2019, 123, 15122-15130.

57 A. M. Jubb and H. C. Allen, ACS Appl. Mater. Interfaces, 2010, 2, 2804-2812.

58 B. S. Yin, S. W. Zhang, H. Jiang, F. Y. Qu and X. Wu, J. Mater. Chem. A, 2015, 3, 5722-5729.

59 H. W. Nesbitt and D. Banerjee, Am. Mineral., 1998, 83, 305315.

60 P. H. Yang, Y. Ding, Z. Y. Lin, Z. W. Chen, Y. Z. Li, P. F. Qiang, M. Ebrahimi, W. J. Mai, C. P. Wong and Z. L. Wang, Nano Lett., 2014, 14, 731-736.

61 M. Toupin, T. Brousse and D. Belanger, Chem. Mater., 2004, 16, 3184-3190.

62 D. Pech, M. Brunet, H. Durou, P. H. Huang, V. Mochalin, Y. Gogotsi, P. L. Taberna and P. Simon, Nat. Nanotechnol., 2010, 5, 651-654.

63 W. Gao, N. Singh, L. Song, Z. Liu, A. L. M. Reddy, L. J. Ci, R. Vajtai, Q. Zhang, B. Q. Wei and P. M. Ajayan, Nat. Nanotechnol., 2011, 6, 496-500.

64 Y. Y. Peng, B. Akuzum, N. Kurra, M. Q. Zhao, M. Alhabe, B. Anasori, E. C. Kumbur, H. N. Alshareef, M. D. Ger and Y. Gogotsi, Energy Environ. Sci., 2016, 9, 2847-2854. 